\title{
Pharmacy Cost Reduction Imperative at United HealthCare
}

\author{
After acquiring another managed care organization, United \\ HealthCare used streamlining and benefits consolidation to improve \\ customer service and reduce the upward trend of pharmacy costs.
}

\section{Eric Bergen}

\section{Author}

ERIC BERGEN is Vice President of Pharmacy Management, United HealthCare.

Copyright 1 1999, Academy of Managed Care Pharmacy, Inc. All rights reserved.
$\mathrm{U}$ nited HealthCare, a managed care organization (MCO) headquartered in Edina, Minnesota, recently instituted pharmacy benefits consolidation and streamlining that reduced its double-digit pharmacy cost trend to less than $6 \%$ in 1997, while improving customer and physician satisfaction through a three-tier pharmacy plan. The methods employed are expected to afford continued savings and benefits through 1998 and beyond.

After United HealthCare acquired MetraHealth in late 1996, the organization served more than 13 million individuals across the United States through preferred provider, health maintenance, and exclusive provider organizations as well as through managed indemnity, point of service, group and individual Medicare, worker's compensation, and specialized provider network products. Approximately 7.5 million pharmacy lives were covered under thousands of different benefit designs, dozens of pharmacy networks, and more than a dozen different formularies nationwide. Each health plan independently managed its pharmacy program. Although United HealthCare had a pharmacy benefit manager (PBM), Diversified Pharmaceutical Services Inc., it became clear that consolidation and streamlining of pharmacy benefits was needed to reduce a trend in which other medical expenses were going down but pharmacy costs continued to increase. Each regional pharmacy market was conducting business in a different way, and the company was disturbed by predictions for a 1997 pharmacy cost trend of $15 \%$.
Rather than try to fix components of the pharmacy service in a piecemeal fashion, United HealthCare and Diversified set up a joint pharmacy steering committee to sort out the problem from a national perspective. The leadership team's main challenge was to reduce the 1997 pharmacy cost trend to zero. The team also set out to increase the average prescription copayment to an $\$ 8$ minimum, sell or renew a national preferred drug list with a copay incentive or closed benefit, maximize generic drug utilization and preferred drug list compliance, and minimize the cost trend in particularly expensive therapeutic classes. Improved customer service and member communication, increased clinical quality programs, improved data integrity and timeliness, and an increase in covered lives through carve-in pharmacy sales were also on the wish list.

Specialty teams addressed the specific needs of strategic markets, such as small group business, large employer groups, Medicare, and Medicaid. These specialty teams proved instrumental in determining how the corporate goals could best be achieved in these niche markets. It became obvious that a great deal of consolidation, including reducing the number of benefit plans and pharmacy networks, would be necessary to meet the goals. An important decision was to give Diversified jurisdiction over the entire United HealthCare pharmacy service. United HealthCare would set direction and make policy decisions and Diversified would execute the plans. This enabled a common face to be presented 
to the various United HealthCare plans, customers, and physician and pharmacy providers, so that all involved knew that Diversified was not instituting changes independently or arbitrarily.

United HealthCare's revised contract with Diversified allowed the PBM to dedicate staff solely to manage the MCO's benefit. Diversified then organized its staff into regional areas, each with its own pharmacy management team. The regionalization was well underway by late 1996, and efforts turned toward replacing the small pocket pharmacy networks with two large national networks. Although costs went up in some local markets, nationally United HealthCare began to realize savings of more than $\$ 1$ million per month by the time the conversion was complete in June of 1997. The Diversified staff also was instrumental in radically changing the United HealthCare pharmacy benefit package structure; the large number of packages offered was reduced to a three-tiered system giving members a choice between generic, branded, and nonpreferred branded products.

A major marketing effort followed development of the new plans. Financial incentives for sales people, the packaging of pharmacy materials, and presentations for existing and prospective employer/ customers all were geared toward a threetiered pharmacy benefit. The change proved very popular with customers.

As an adjunct to the new benefit design, the existing 17 formularies were consolidated into a single national preferred drug list. The revision was much less traumatic than expected because, upon review, United Health-Care found that $95 \%$ of the drugs on the 17 existing formularies were the same on each list. Only $5 \%$ of all listed drugs were involved in the change, and the utilization of one national list proved far more efficient.

The nationwide restructuring also called for Diversified to analyze all disease management models being used in each United HealthCare market to identify those that were both producing clinical benefits and saving money. Late in 1997, selected modules were standardized to create a central disease management system available to each market. In addition, more sophisticated disease management modules were developed using pharmacy information and pre- . scription-writing profiles. Both patients and physicians were educated via a letter campaign on disease management models for conditions such as diabetes, heart disease, osteoporosis, and depression. Educational activities aimed at increasing physicians' awareness of disease management guidelines also are well underway, and the Diversified physician profile program has been linked to the disease management program. Physi- cians not meeting established disease management guidelines are identified and targeted with specific educational efforts. United HealthCare has proceeded on the belief that linking disease management and pharmacy services ensures that pharmacy does not become a separate silo in the United HealthCare system.

As a result of these changes, United HealthCare reduced its 1997 pharmacy cost trend to $5.95 \%$ and realized clinical benefits as well, including improved compliance with drug therapy, as many more patients have prescriptions refilled according to physicians' instructions. United HealthCare also has found that first-line drugs are being used more often. Favorable feedback from physicians has been coming in, and United HealthCare has a stronger, more positive reputation among physician providers. As more United HealthCare markets incorporate the new strategies, United HealthCare expects that the reduced pharmacy cost trend will be sustained.

United HealthCare now is developing plans to extend the improvements to self-funded clients, to seniors programs, and to other business lines in which the company is involved. The key to United HealthCare's success so far has come through focusing on the basics, participating in joint problem solving with its PBM, and creating teams to find the best work flow processes. 